\title{
Cirugía de emergencia por colecistitis aguda debido a fístula colecistocolónica
}

\section{Emergency surgery for acute cholecystitis caused by cholecystocolonic fistula} \author{
Sandra Terrazas Díaz ${ }^{4, f}$ \\ ${ }^{1}$ Hospital Regional Honorio Delgado. Arequipa, Perú. \\ ${ }^{2}$ Asociación de Médicos Residentes del Hospital Regional Honorio Delgado. Arequipa, Perú. \\ ${ }^{3}$ Hospital Goyeneche, Arequipa, Perú. \\ ${ }^{4}$ Hospital Cívico Policial MY. Julio Pinto Manrique. Arequipa, Perú. \\ ${ }^{a}$ Médico residente de cirugía general, ORCID: https://orcid.org/0000-0002-4128-8990 \\ ${ }^{b}$ Médico especialista en cirugía general, ORCID: https://orcid.org/0000-0003-3578-5218 \\ ${ }^{c}$ Médico especialista en cirugia general, ORCID: https://orcid.org/0000-0001-9593-3433 \\ ${ }^{d}$ Médico especialista en cirugia general, ORCID: https://orcid.org/0000-0003-2455-1168 \\ ${ }^{e}$ Médico especialista en cirugia general, ORCID: https://orcid.org/0000-0002-0330-5067 \\ † Médico especialista en cirugia plástica, ORCID: https://orcid.org/0000-0002-4581-8709
}

Angel F. Vera-Portilla ${ }^{1,2, a}$, Walter Vera-Portilla, ${ }^{1, b}$, Jose Luis Galdós ${ }^{1, c}$, Edwin Bustinza Flores ${ }^{3, d}$, Darling Cornejo Valencia ${ }^{1, e}$,

\author{
Correspondencia: \\ Angel F. Vera Portilla \\ angel.veraportilla218@gmail.com \\ Recibido: 27 de abril 2021 \\ Aprobado: 15 de julio 2021 \\ Publicación en línea: 5 de agosto 2021 \\ Conflictos de interés: Los autores \\ declaran no tener conflictos de interés. \\ Fuente de financiamiento: \\ Autofinanciado \\ Citar como: Vera-Portilla A, Vera-Portilla \\ W, Galdós JL, Bustinza E, Cornejo D, \\ Terrazas S. Cirugía de emergencia \\ por colecistitis aguda debido a fistula \\ colecistocolónica. An Fac med. \\ 2021;82(2):150-4. DOI: https://doi. \\ org/10.15381/anales.v82i2.21036
}

An Fac med. 2021;82(2):150-4. / DOI: https://doi.org/10.15381/anales.v82i2.21036.

\section{Resumen}

La fístula colecistocolónica (FCC) es una complicación poco común de la colelitiasis. A menudo son asintomáticas, de difícil diagnóstico preoperatorio a pesar del apoyo radiológico, y se descubren de manera incidental perioperatoriamente. Presentamos el caso de una mujer con un cuadro de colecistitis aguda, la cual fue intervenida por laparoscopia, y se evidenció una FCC, la cual fue resuelta mediante conversión a cirugía abierta. La FCC puede complicarse y simular cuadros abdominales agudos. Se debe tener en cuenta en adultos mayores, con historia de colelitiasis, y vesículas escleroatróficas con adherencias. En la literatura se han descrito muy pocos casos, y ninguno en nuestro medio. Presentamos un caso de FCC que ingresó como una colecistitis aguda, y su diagnóstico y tratamiento fueron durante su cirugía.

Palabras clave: Colecistitis Aguda; Colelitiasis; Fístula Biliar; Cirugía; Emergencias (fuente: DeCS BIREME).

\section{Abstract}

Cholecystocolonic fistula (CCF) is a rare complication of cholelithiasis. They are often asymptomatic, difficult to diagnose preoperatively, it despite radiological support, and they are discovered incidentally perioperatively. We present the case of a woman with acute cholecystitis, who was operated by laparoscopy, and a CCF was evidenced, it was resolved by conversion to open surgery. FCC can be complicated and simulate acute abdominal symptoms. It should be taken into account in older adults with a history of cholelithiasis and scleroatrophic vesicles with adhesions. Very few cases have been described in the literature, and none in our country. We present a case of FCC that was admitted as acute cholecystitis, and the diagnosis and treatment of it were during her surgery.

Keywords: Acute Cholecystitis; Cholelithiasis; Biliary Fistula; Surgery; Emergencies (source: MeSH NLM). 


\section{INTRODUCCIÓN}

Las fístulas colecistocolónicas (FCC) son el resultado de una comunicación entre la vesícula biliar (VB) y el lado derecho del colon ${ }^{(1)}$, es una de las fístulas bilioentéricas (FBE) más infrecuente $(8-26.5 \%)^{(2-5)}$ y generalmente aparece como complicación tardía de las colecistitis crónicas litiásicas ${ }^{(1,6,7,8)}$, presente en el 0,06-0,14\% de las colecistectomías ${ }^{(8,9,10)}$. También se han reportado otros factores como traumatismos, cirugías previas, colecistostomía, heridas abdominales iatrogénicas o enfermedad maligna ${ }^{(8)}$. Inclusive como complicaciones raras del carcinoma de VB ${ }^{(8)}$, la colecistitis xantogranulomatosa ${ }^{(5)} \mathrm{O}$ el síndrome de Mirizzi ${ }^{(11)}$. Y afecta con mayor frecuencia a las mujeres en edad avanzada (sexta o séptima década de la vida) ${ }^{(1,6,12,13)}$.

Los síntomas de la FCC suelen ser mínimos e inespecíficos, siendo la diarrea crónica el más frecuente ${ }^{(10)}$, debido al efecto directo de las sales biliares sobre la mucosa colónica (enteropatía colerética), lo que además da coloración verdínica a la materia fecal ${ }^{(2,4)}$. Los pacientes se hospitalizan principalmente por dolor en hipocondrio derecho (HCD), rigidez muscular, náuseas, vómito, ictericia y colangitis leve, moderada o severa ${ }^{(4)}$; o raramente como hemorragia digestiva baja (13). Habitualmente no causan obstrucción intestinal (2,4), y también pueden cursar de manera asintomática ${ }^{(4)}$.

Las imágenes juegan un rol fundamental en su detección y manejo. El coIon por enema parece ser el mejor método para arribar al diagnóstico y confirmar su existencia ${ }^{(2,10)}$. La CPRE es invasiva y está restringida a pacientes con ictericia y/o coledocolitiasis ${ }^{(14)}$. La colangioresonancia proporciona mejor información sobre la estructura y el contenido del árbol biliar ${ }^{(12)}$. La tomografía permite la demostración del sitio de obstrucción y el lugar de la fístula ${ }^{(8)}$. La radiografía puede mostrar los signos clásicos de íleo biliar $^{(2,4)}$. La ecografía es menos útil, pero muestra una vesícula contraída, irregular, con o sin cálculos, falta de visualización vesicular y neumobilia ${ }^{(2,4,13)}$. A pesar de todos estos estudios, el diagnóstico preoperatorio sólo se logra en el 8-17\% de los casos ${ }^{(8,10,12)}$ y en general se las identifica en la cirugía ${ }^{(2,12)}$. Esta baja tasa de detección se debe a la poca especificidad de los síntomas ${ }^{(2,13)}$ y a la baja sensibilidad de los métodos diagnósticos ${ }^{(10)}$.

El tratamiento de la FCC puede ser conservador ${ }^{(10)}$ o invasivo; y quirúrgico cuando se manifiesta sus complicaciones ${ }^{(4)}$, como sepsis, íleo biliar, obstrucción y hemorragia ${ }^{(5,6)}$.

En la literatura se han descrito muy pocos casos de FCC, y ninguno en nuestro medio. Por lo que presentamos un caso de FCC que fue un hallazgo durante una intervención de emergencia por una colecistitis aguda, la cual fue resuelta con resección y sutura del trayecto fistuloso. Presentamos el caso de una mujer de 49 años, con antecedente de diabetes mellitus y diarreas de coloración "verdosa", que 9 días antes de su ingreso presentó dolor en HCD, que aumentó progresivamente en intensidad, asociándose a náuseas. A su ingreso por emergencia se encontró hemodinámicamente estable, presentando dolor objetivo en HCD, signo de Murphy negativo. La ecografía informó una vesícula escleroatrófica poco valorable, asociada a colelitiasis (3 imágenes de $3 \mathrm{~mm}$ ). Además, la analítica mostró un hemograma con leucocitos 6300/mm³, glucosa $297 \mathrm{mg} / \mathrm{dL}$, fosfatasa alcalina: $366 \mathrm{U} / \mathrm{L}$, por lo que se le
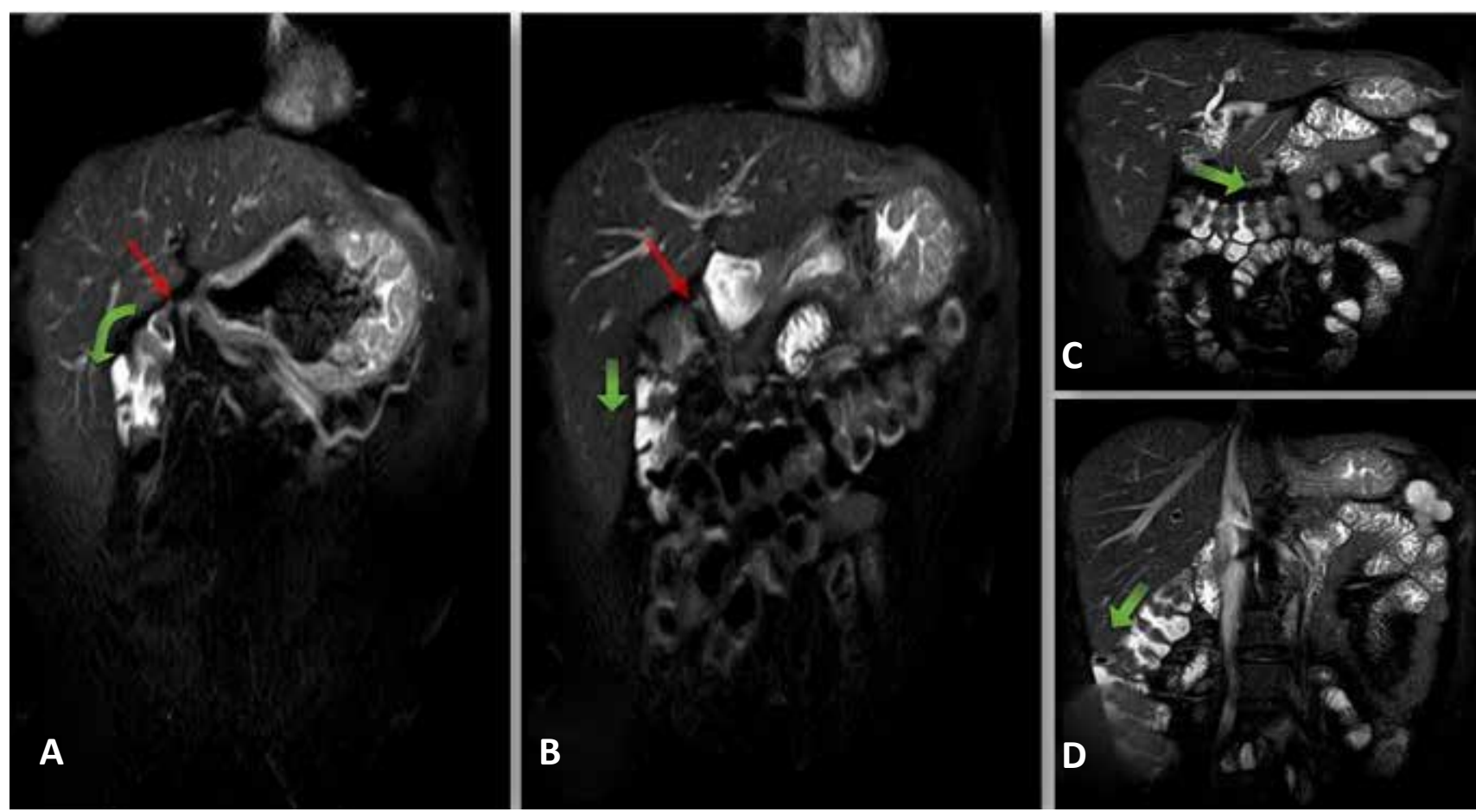

Figura 1. Colangioresonancia, corte coronal. A y B, corte coronal mostrando la FCC posterior a la vesícula (flecha roja) y el pase de contraste hacia ángulo colólino derecho. C, paso de contraste hacia colon transverso (flecha verde). D, paso de contraste hacia colon ascendente (flecha verde). 

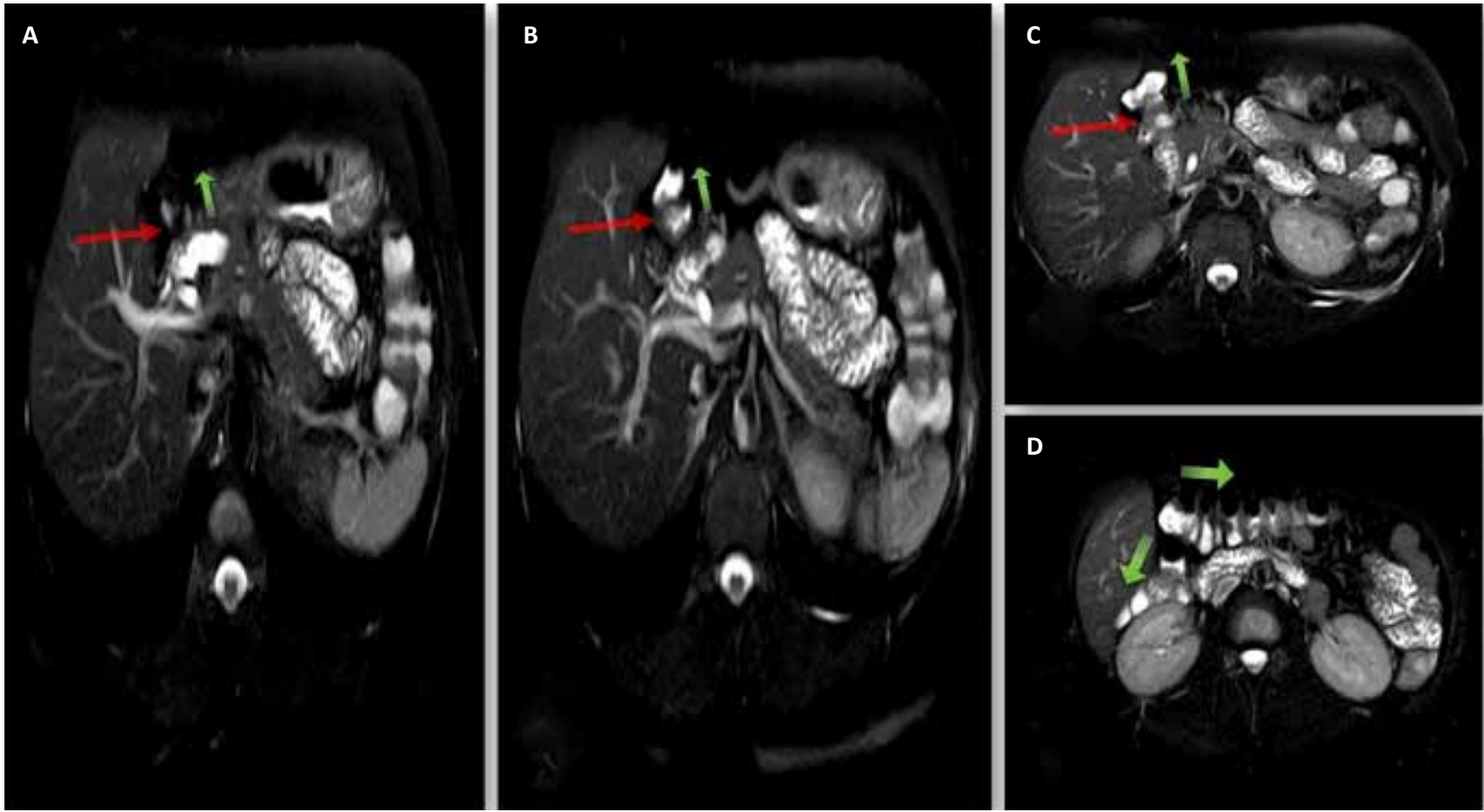

Figura 2. Colangioresonancia, corte transversal. A, B y C, mostrando la FCC posterior a la vesícula biliar (flecha roja), y paso de contraste hacia colon transverso (flecha verde). D, paso de contraste hacia colon transverso y colon ascendente (flechas verdes).

realizó una colangioresonancia, la cual no evidenció cálculos ni dilatación de vía biliar, aunque mostró paso de contraste hacia intestino grueso (Figuras 1,2 y 3). El resto de los exámenes dentro de parámetros normales.
Catalogada como colecistitis crónica litiásica, recibió tratamiento médico inicial por cuadro de diabetes descom-
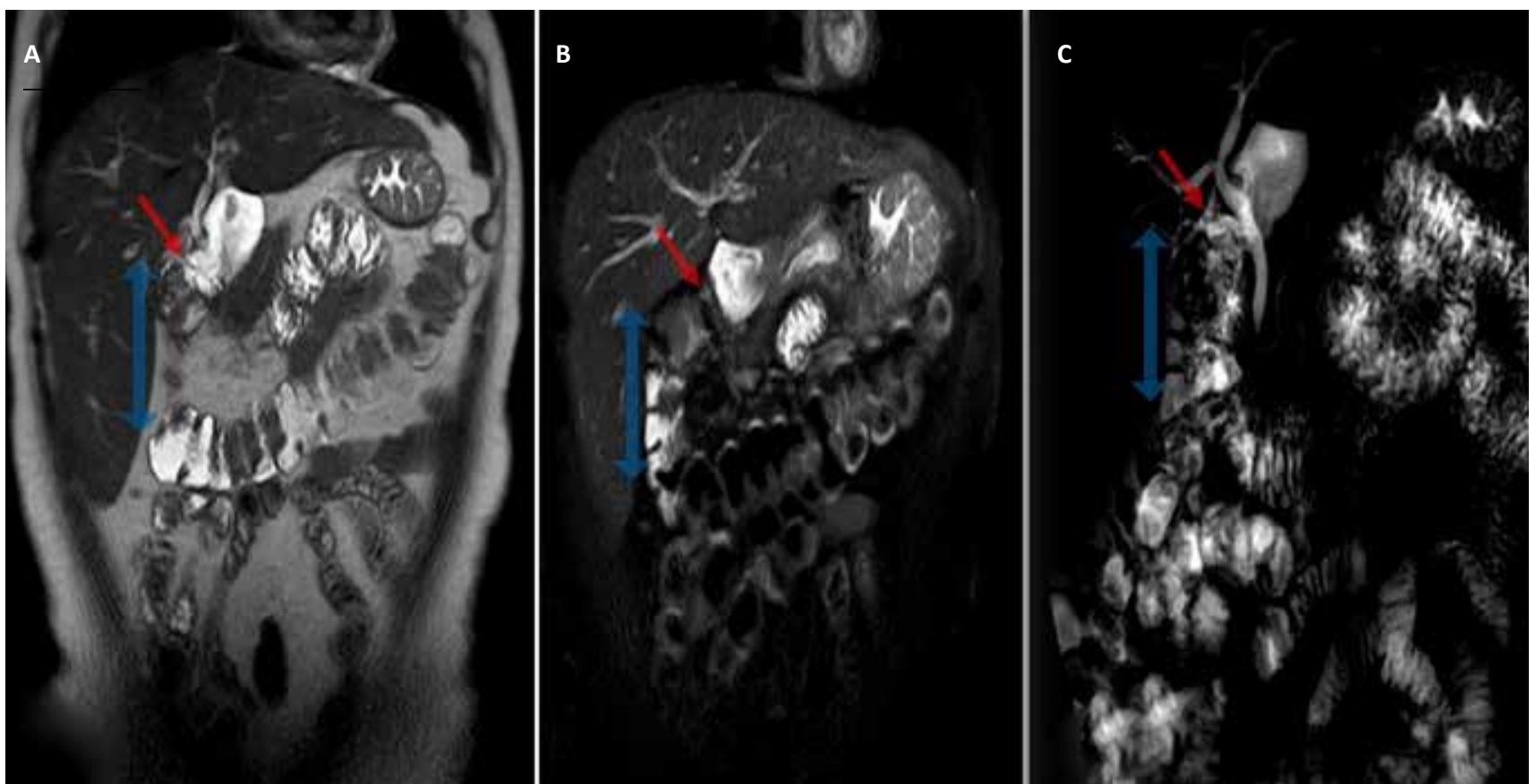

Figura 3. Colangioresonancia. A y B, corte coronal, segmento de ángulo colónico derecho y parte del colon transverso traccionado hacia arriba (flecha azul). C, reconstrucción de vesícula y vías biliares, incidencia lateral derecha, en la que se muestra la FCC posterior a la vesícula (flecha roja), y la porción de colon transverso traccionado hacia arriba (flecha azul). 

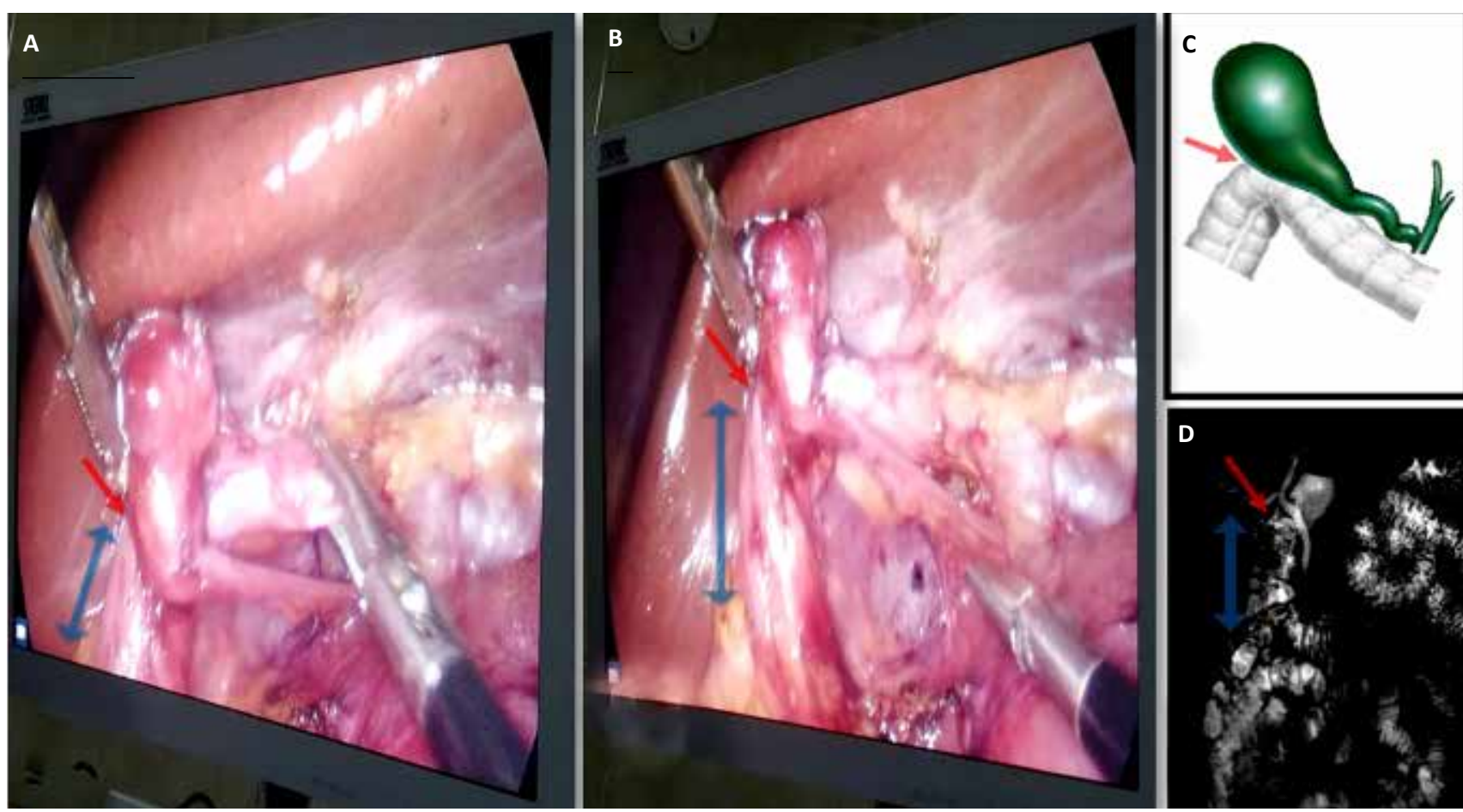

Figura 4. A y B, hallazgo intraoperatorio, mostrando la FCC posterior a la vesícula (flecha roja), y el segmento de colon transverso traccionado hacia arriba (flecha azul). C, representación gráfica de la FCC posterior a la vesícula (flecha roja). D, reconstrucción de vesícula y vías biliares, incidencia lateral derecha, en la que se muestra la FCC posterior a la vesícula (flecha roja), y la porción de colon transverso traccionado hacia arriba (flecha azul).

pensada luego del cual fue intervenida quirúrgicamente. Durante la cirugía laparoscópica se evidenció abundantes adherencias, una vesícula pequeña de aproximadamente $2,5 \times 2 \mathrm{~cm}$, de paredes engrosadas, sin evidencia de cálculos, y una fístula colecistocolónica entre vesícula y colon transverso (Figura 4), por lo que se decidió convertir y realizar una colecistectomía directa y rafia de colon. Posteriormente el paciente cursó con buena evolución, recibiendo antibiótico terapia, tolerando dieta al segundo día, y es dada de alta los 7 días, sin complicaciones.

\section{DISCUSIÓN}

La FCC es la segunda FBE luego de las colecistoduodenales ${ }^{(2,10)}$, y es una complicación infrecuente y tardía de la colelitiasis, con una incidencia de 1/1000 colecistectomías ${ }^{(1)}$. Su etiología puede estar relacionada a un proceso inflamatorio de la VB, de larga duración, causado por cálculos ${ }^{(8,10)}$. La inflamación aguda en asociación con la obstrucción del conducto cístico, permite la adhesión de la VB a los órganos contiguos ${ }^{(1,4,12)}$. Durante este proceso inflamatorio crónico, asociado a un aumento de presión dentro de la vesícula, generaría una ulceración e isquemia en su pared, lo que provocaría erosión y finalmente la FCC ${ }^{(1,10,12)}$. Sin embargo, el cáncer, los traumatismos, las infecciones amebianas, la úlcera péptica y la diverticulitis, también se han implicado en la etiología (1). Este cuadro, normalmente inadvertido, evoluciona con la migración del cálculo al lumen intestinal, con cólicos intestinales a repetición y movilización de este a través de su lumen, produciendo eventualmente un cuadro obstructivo ${ }^{(13)}$.

Nuestro caso trató de una mujer ${ }^{(8,10,15)}$, con antecedente de síntomas de diarrea crónica "verdosa" $(2,10)$, pero no de colelitiasis ${ }^{(2,7,7,11)}$. La diarrea se debería a una alteración de la circulación entero biliar de las sales biliares, que al no absorberse en el íleon distal llegan al colon y estimulan la secreción de agua y electrolitos por la mucosa colónica. Además, las sales biliares forman las micelas y permiten la absorción de las grasas y las vitaminas li- posolubles, produciendo mala absorción de la vitamina K, y consecuentemente una alteración de concentración de protrombina (CP) ${ }^{(10)}$.

Los pacientes con FCC frecuentemente son asintomáticos. Cuando son sintomáticos, presentan diarrea, dolor abdominal, ictericia, fiebre, náuseas, vómitos, esteatorrea y pérdida de peso ${ }^{(1)}$. Además, la tríada de la aerobilia, la alteración del coagulograma (mala absorción de la vitamina K) y la diarrea crónica, fue propuesta como patognomónica ${ }^{(1,5,10)}$. En raras ocasiones la FCC causa obstrucción intestinal secundaria a íleo biliar ${ }^{(9,15)}$. También, el dolor en HCD rara vez se encuentra presente, $y$ aunque, una FCC potencialmente podría infectar a la VB y el sistema biliar, la ictericia y la fiebre rara vez se informan como síntomas iniciales ${ }^{(10)}$. En nuestro caso, la paciente ingresó con un cuadro clínico de colecistitis aguda, no mostró la triada sintomática ${ }^{(10)}$, ni un patrón colestásico clásico ${ }^{(1,5)}$, salvo una elevación discreta de fosfatasa alcalina ${ }^{(11)}$, por lo que una vez realizada la colangioresonancia, se programó su intervención. 
Un diagnóstico preoperatorio es fundamental para asegurar un manejo adecuado ${ }^{(14)}$. Se debe sospechar cuando la ecografía revela contacto entre la VB y la pared intestinal inflamada en una paciente anciana, con una larga historia de colecistitis (>5 años); o si se encuentra un borde mal definido entre la VB y el tracto gastrointestinal vecino, en la tomografía ${ }^{(14)}$. A nuestra paciente no se le realizó un enema baritado ${ }^{(2)}$, ni tomografía ${ }^{(6,8,11,15)}$; además, la ecografía no mostró aerobilia ${ }^{(10)}$ y la colangiografía no describió ninguna FBE ${ }^{(10)}$.

La FCC no diagnosticada en las imágenes preoperatorias puede plantear un problema para el cirujano, y puede verse obligado a convertir una laparoscopía electiva, en un procedimiento abierto complejo ${ }^{(1)}$. Como en nuestro caso, en que se programó una colecistectomía laparoscópica, y el hallazgo fue intraoperatorio, el cual asociado a las adherencias, motivó la decisión de su conversión ${ }^{(4)}$ y se realizó una colecistectomía y cierre del trayecto fistuloso ${ }^{(2,5,7)}$.

Usualmente, las fístulas se descubren de manera incidental por complicaciones como obstrucción intestinal por íleo biliar ${ }^{(9,15)}$, hemorragia digestiva baja ${ }^{(7,13)}$; o colangitis aguda, peritonitis biliar y cirrosis biliar (1). Diferente a nuestro caso, en el que se debió a un cuadro de colecistitis aguda litiásica.

El tratamiento en pacientes asintomáticos, sin complicaciones y con comorbilidad asociada, puede ser conservador, mediante CPRE ${ }^{(10)}$, antibióticos y suplementos de vitaminas liposolubles ${ }^{(4,5)}$. Las indicaciones de cirugía son la presencia de complicaciones ${ }^{(4)}$, e incluye drenaje biliar laparoscópico o abierto, colecistectomía y resección de fístula (con o sin resección intestinal segmentaria y anastomosis) ${ }^{(5,7,12)}$.

El tratamiento quirúrgico presenta controversias como la necesidad o no de una colostomía o la factibilidad del cierre de la FCC mediante una laparoscopia.
En la actualidad el enfoque inicial es laparoscópico, aunque se reportan largos tiempos operatorios y un número considerable de conversiones $(1,10,12)$ debido a hemorragias, adherencias locales graves y dificultades técnicas en la sutura intestinal (12,14); corriendo el riesgo de provocar complicaciones como perforación iatrogénica del colon y la peritonitis fecal (1). Al mismo tiempo, si la estructura anatómica no está clara, la colecistectomía parcial es segura y eficaz ${ }^{(14)}$. Por todo ello, algunos autores afirman que el tratamiento debe ser una colecistectomía abierta con cierre de la fístula ${ }^{(1)}$. Por otro lado, si el paciente presenta un desequilibrio electrolítico, sepsis u otros trastornos causados por la obstrucción intestinal, bajo ninguna circunstancia se debe reparar o cerrar la fístula, debido al mayor riesgo de contaminación adicional por disección extra en el área de la VB ${ }^{(12)}$, por lo que se recomienda únicamente la enterotomía y extracción del lito ${ }^{(3,6)}$.

En conclusión, la FCC es un caso infrecuente, el cual puede presentarse como un cuadro abdominal agudo (colecistitis aguda). Y debe tenerse en cuenta en pacientes adultos mayores, con larga historia de colelitiasis, en los que se encuentra VB escleroatrófica, de paredes gruesas y con múltiples adherencias; por lo que se recomienda ampliar con un estudio de imagen complementario. Además, existe una tríada que consiste en: diarrea crónica, alteración de $\mathrm{CP}$, y neumobilia. El diagnóstico preoperatorio es difícil, pero permite optar por un tratamiento menos invasivo o planificar la intervención.

\section{REFERENCIAS BIBLIOGRÁFICAS}

1. Abbasi S, Khan DB, Khandwala K, Raza R, Memon WA. Cholecystocolonic Fistula. Cureus J Med Sci. 2019;11(6):1-7. DOI: 10.7759/cureus.4874

2. Palau JA, Rae E. Fistula colecistocolónica. Rev del Hosp Priv Comunidad. 2005;8(1):1-4.
3. Díaz-Rosales J de D, Morales-Polanco S. Sangrado de tubo digestivo alto debido a fístula colecistoduodenal: Hallazgo quirúrgico. Arch Med. 2020;20(1):221-225. DOI: https://doi.org/10.30554/archmed.20

4. Brito M M del R, Gallardo A DF, Ortega S ME, Serrano A JJ. Fistula colecistocolónica y colecistoduodenal simultáneas en un paciente con colecistolitiasis. Rev Med Ateneo. 2017;19(2):160-6.

5. Morare N, Mpuku L, Ally Z. Xanthogranulomatous cholecystitis complicated by a cholecysto-colonic fistula and liver abscesses. JSCR. 2020;7:1-4. DOI: 10.1093/jscr/rjaa176

6. Hajjar R, Létourneau A, Henri M, Heyen F, Latulippe $\mathrm{J}-\mathrm{F}$, Poirier $\mathrm{M}$, et al. Cholecystocolonic fistula with a giant colonic gallstone: the mainstay of treatment in an acute setting. JSCR. 2018;10:1-3. DOI: 10.1093/ jscr/rjy278

7. Yan $\mathrm{H}-\mathrm{L}$, Lin $\mathrm{B}$, Lu Q, Lei T-T, Ma H-S, Yang J-L. Gallbladder bleeding along with cholecystocoIonic fistula: a case report. Gastroenterol Rep. 2021;9(1):81-84. DOI: 10.1093/gastro/goaa034

8. Sunakawa T, Ko K, Moriyasu R, Nishida Y, Otagiri N, Tauchi K. Emergency surgery for acute cholecystitis associated with cholecystocolonic fistula caused by gallbladder cancer: a case report. JSCR. 2020;9:13. DOI: $10.1093 /$ jscr/rjaa305

9. Mahmood F, Ajayi O, Ahmed M, Akingboye AA Unusual case of cholecystocolonic fistula secondary to megabowel. BMJ Case Rep. 2020;13(12):237836. DOI: 10.1136/bcr-2020-237836

10. Manazzoni D, Málaga I, Curvale C, Guidi M, Maria J De, Matano R. Fístula colecistocolónica : abordaje dual. Reporte de un caso. Acta Gastroenterol Latinoam. 2020;50(3):360-4.

11. Esparza Monzavi CA, Peters X, Spaggiari M. Cholecystocolonic fistula: A rare case report of Mirizz syndrome. Int J Surg Case Rep. 2019;63:97-100. DOI: 10.1016/j.ijscr.2019.09.023

12. Gonzalez-Urquijo M, Rodarte-Shade M, LozanoBalderas G, Gil-Galindo G. Cholecystoenteric fistula with and without gallstone ileus: A case series. Hepatobiliary Pancreat Dis Int. 2020;19(1):36-40. DOI: 10.1016/j.hbpd.2019.12.004

13. Guerra SC, Corral BR, Schalper CK. Hemorragia digestiva baja masiva por fístula colecistocolónica: presentación de caso clínico y revisión de la literatura. Rev chil cir. 2003;55(6):648-50.

14. Li XY, Zhao $X$, Zheng $P$, Kao XM, Xiang XS, Ji $W$. Laparoscopic management of cholecystoenteric fistula: A single-center experience. J Int Med Res. 2017;45(3):1090-1097. DOI: 10.1177/0300060517699038

15. Soto Sanchez A, Sánchez Gonzáles J, Amir Nicolau B, Marrero Marrero P, Del Pino Monzón J, Díaz Mejías J, et al. Íleo biliar colónico secundario a fístula colecistocolónica. Rev Española Investig Quirúrgicas. 2012;15(1):25-6. 